G.Gambirasio

Correction for detector's specificity and sensitivity in contingency tables

$1 / 26$

\title{
Correction for detector's specificity and sensitivity in contingency tables
}

Giorgio Gambirasio (giga@uol.com.br)

\begin{abstract}
A methodology has been developed to correct the influence of detector's specificity and sensitivity on the contingency table used to evaluate how much an effect (like disease status) depends on a given cause (like taking a certain drug). The work is based on a deterministic (non-probabilistic) approach to contingency tables analysis.
\end{abstract}

Keywords: contingency tables, specificity, sensitivity, disease screening, correlation, biological sciences, medical research.

\section{DRAMATIS PERSONAE}

Dramatis personae (drama's masks) is the Latin name of characters' list in a play. This expression has been frequently used in old classic theater, less so in modern times and possibly never in scientific papers. Here, it is an expanded version of, and more informative than, a simple list of keywords.

A detector generically is an apparatus (or methodology, procedure, means of diagnostic), used in medical research and practice, designed to separate subjects into positive ones (subjects found to suffer from a certain disease, for simplicity here called baddies) and negative ones (subjects found not to suffer from the disease, for simplicity here called goodies).

A perfect detector perfectly distinguishes between baddies and goodies, so that all subjects separated as positive are truly baddies, and all subjects separated as negative are truly goodies. Its specificity and sensitivity (see below) are both equal to 1 or $100 \%$.

An imperfect detector, on the contrary, at least presents one of two types of imperfection:

a) Type I Error, when some subjects that do not suffer from the disease (goodies) are counted as positive (false baddies). Parameter $\beta(0 \leq \beta \leq 1)$ is defined as the quotient of false baddies to total goodies. Detector's Specificity $=1-\beta$.

b) Type II Error, when some subjects that do suffer from the disease (baddies) are counted as negative (false goodies). Parameter $\gamma(0 \leq \gamma \leq 1)$ is defined as the quotient of false goodies to total baddies. Detector's Sensitivity $=1-\gamma$.

Detector's parameters are how specificity, sensitivity, $\beta$, and $\gamma$ are referred to.

A careful operator is a person who is aware that the detector is imperfect, knows its specificity and sensitivity, and follows the methodology here introduced in order to correct the influence of imperfections. 
G.Gambirasio

Correction for detector's specificity and sensitivity in contingency tables

A careless operator behaves as if an imperfect detector were perfect. This operator does not follow a corrective methodology, therefore leading to conclusions totally affected by detector's imperfections.

Probabilistic approach means using Theory of Probability and Statistics as tools to analyze contingency tables. This approach is occasionally mentioned in this paper.

Deterministic approach means using elementary Set Theory as a tool to analyze contingency tables. This approach is presented in a previous paper $\left({ }^{1}\right)$ and is used throughout the present paper. We suggest reading paper $\left({ }^{1}\right)$ for reference to symbols, equations, and formulas.

\section{Symbols used to denote sets and their contents:}

Sets are indicated as usually done: set $\mathrm{K}=\{$ rose, carnation, daisy, tulip $\}$; $\mathrm{L}=$ (baddies) or $\mathrm{L}=\{$ baddies $\}$.

Content of a set is the number of its members. Content is indicated as \#(K)=4.

If there are 250 baddies in the experiment, then $\#$ (baddies) $=250$.

Cells of contingency tables are numbers, that is, they are contents of sets, not the set themselves.

Examples:

$\#(T)=$ total number of subjects in an experiment; $\#(B)=$ total number of baddies;

$\#(G)=$ total number of goodies;

$\#(\operatorname{Pos})=$ total number of subjects found to be baddies by a detector;

$\#(\mathrm{Neg})=$ total number of subjects found to be goodies by a detector;

$\#(\mathrm{~A})$ = total number of subjects performing the specified activity;

$\#(I)=$ total number of subjects not performing the specified activity.

Complement of a set $\mathrm{K}$ is indicated as not-K.

Properties : $\mathrm{K} \cup$ not- $\mathrm{K}=\mathrm{T} ; \#(\mathrm{~K})+\#($ not- $\mathrm{K})=\#(\mathrm{~T})$. Examples: $\mathrm{G}=$ not-B; $\mathrm{I}=$ not-A.

Some important expressions and quantities defined in $\left(^{1}\right)$ :

Proportion of set $\mathrm{X}$ content relative to set $\mathrm{Y}$ content $=\mathrm{P}(\mathrm{X} \mid \mathrm{Y})=\#(\mathrm{X} \cap \mathrm{Y}) / \#(\mathrm{Y})$;

Equation defining independence of $\mathrm{X}$ from $\mathrm{Y}: \mathrm{P}(\mathrm{X} \mid \mathrm{Y})=\mathrm{P}(\mathrm{X} \mid$ not- $\mathrm{Y})$;

Dependence evaluator (or association, correlation evaluator) of $\mathrm{X}$ upon $\mathrm{Y}$ is evaluator $\operatorname{dep}(\mathbf{X} \mid \mathbf{Y})=[\mathbf{P}(\mathbf{X} \mid \mathbf{Y}-\mathbf{P}(\mathbf{X} \mid$ not-Y $)] /[\mathbf{P}(\mathbf{X} \mid \mathbf{Y})+\mathbf{P}(\mathbf{X} \mid$ not-Y $)]$

Contingency table is a table conveniently displaying the results of an experiment designed to verify the effects of an activity (like taking a specific drug) on health status of subjects suffering from a certain disease. Only $2 \times 2$ contingency table are considered.

Prevalence, named $\alpha$, is the fraction of peoples suffering from the disease in the population from which the sample is extracted: $\alpha=\#(B) / \#(T)$. 
G.Gambirasio

Correction for detector's specificity and sensitivity in contingency tables

\section{INTRODUCTION}

This paper discusses problems which arise in screening for disease or in analyzing contingency tables when data are supplied by an imperfect detector (a detector suffering from specificity and sensitivity).

The approach to the problems is the deterministic approach, as presented in $\left({ }^{1}\right)$. The purpose is to develop a methodology capable of correcting the effects of detector's imperfections.

In probabilistic approach the action of a perfect detector is routinely and abundantly described in the literature. The results are the contents of set B (all the baddies) and its complement set $\mathrm{G}$ (all the goodies). In deterministic approach $\left({ }^{1}\right)$, the action of a perfect detector similarly results in sets $B$ and $\mathrm{G}$.

The role of an imperfect detector will only be studied here with tools of deterministic approach $\left(^{1}\right)$.

As an example of disease screening with an imperfect detector, consider a sample set $\mathrm{T}$ extracted from a certain population, such that \#(T) is the total number of subjects to be analyzed by a detector. The objective of the analysis is to separate the subjects suffering from a specified disease (thus belonging to set $\mathrm{B}$, that is, to the baddies) from those who do not suffer from the disease (thus belonging to set $\mathrm{G}$, that is, to the goodies).

Since set $T=B \cup G$, and sets $B, G$ are disjoint, the content of $T$ is the sum of their contents: $\#(T)=\#(B)+\#(G)$. A parameter $\alpha(0 \leq \alpha \leq 1)$ may be defined, such that it measures the fraction of baddies or of goodies in $\mathrm{T}$ : $\#(B)=\alpha . \#(T) ; \#(G)=(1-\alpha)$. $\#(T)$. In the literature, this parameter is called prevalence, being a property of the population from which the sample is extracted.

The detector really separates the content of T into two disjoint sets Pos and Neg (meaning the positive and the negative results from the screening, respectively), but due to imperfections it happens that:

1) since the detector suffers from Type I error (i.e. false positive), set Pos only contains a fraction of total baddies (true baddies) plus a number of goodies (false baddies);

2) since the detector also suffers from Type II error (i.e. false negative), set Neg only contains a fraction of total goodies (true goodies) plus a number of baddies (false goodies).

Figure 1 (a) symbolizes the results (B and $\mathrm{G}$ ) of a screening of set $\mathrm{T}$ by a perfect detector. Set $\mathrm{B}$ has been painted gray.

And Figure 1 (b) symbolizes the results (Pos and Neg) of a screening of the same set $\mathrm{T}$ by an imperfect detector. Set Pos has been painted gray.

It is an easy thing to suspect that the two grayed areas do not contain the same subjects, and this question will be discussed at length. Table I summarizes the relations among sets, their contents, and detector's characteristics. 
G.Gambirasio

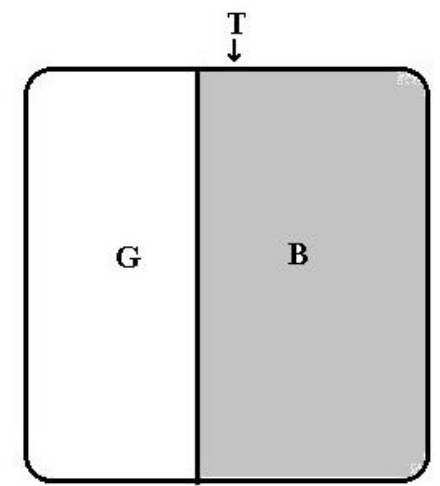

(a)

A perfect detector sees set $B$ (grayed area)

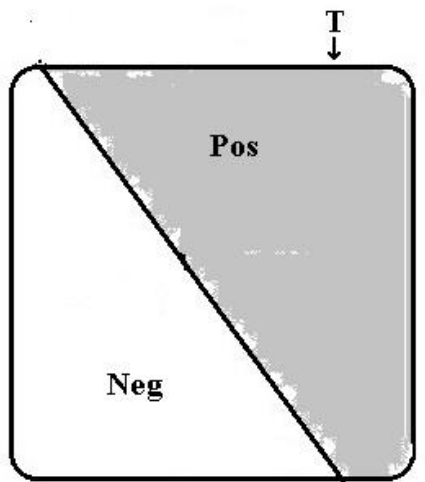

(b)

An imperfect detector sees set Pos (grayed area)

Figure 1 - Total set $\mathrm{T}$ as seen by (a) a perfect detector or (b) an imperfect detector.

Table I - Relations among sets and their contents

\begin{tabular}{|c|c|c|c|}
\hline $\begin{array}{l}\text { Results from } \\
\text { screening by } \\
\text { an imperfect } \\
\text { detector } \downarrow\end{array}$ & $\begin{array}{c}B=\text { set of baddies in } \mathbf{T} \\
\#(B)=\alpha . \#(T)\end{array}$ & $\begin{array}{c}\mathbf{G}=\text { set of goodies in } \mathbf{T} \\
\#(\mathbf{G})=(1-\alpha) . \#(T)\end{array}$ & Totals \\
\hline $\begin{array}{c}\text { Set of positive } \\
\text { subjects } \\
\text { Pos }\end{array}$ & $\begin{array}{c}(\text { true baddies })= \\
\quad=\mathrm{B} \cap \text { Pos } \\
\text { Sensitivity }=1-\gamma \\
\#(\text { true baddies })= \\
=(1-\gamma) . \#(B)\end{array}$ & $\begin{array}{c}(\text { false baddies })= \\
\quad=\mathrm{G} \cap \text { Pos } \\
\#(\text { false baddies })= \\
\quad=\beta . \#(\mathrm{G})\end{array}$ & $\begin{array}{c}\text { Total of subjects } \\
\text { found positive } \\
\quad \#(\text { Pos })= \\
=\#(\text { true baddies })+ \\
\# \text { (false baddies })\end{array}$ \\
\hline $\begin{array}{c}\text { Set of negative } \\
\text { subjects } \\
\text { Neg }\end{array}$ & $\begin{array}{c}(\text { false goodies })= \\
\quad=\mathrm{B} \cap \mathrm{Neg} \\
\#(\text { false goodies })= \\
\quad=\gamma . \#(\mathrm{~B})\end{array}$ & $\begin{array}{c}(\text { true goodies })= \\
\quad=\mathrm{G} \cap \mathrm{Neg} \\
\text { Specificity }=1-\beta \\
\#(\text { true goodies })= \\
=(1-\beta) . \#(\mathrm{G})\end{array}$ & $\begin{array}{c}\text { Total of subjects } \\
\text { found negative } \\
\quad \#(\text { Neg })= \\
=\#(\text { false goodies })+ \\
+\#(\text { true goodies })\end{array}$ \\
\hline Totals & $\begin{aligned} & \text { Total of baddies } \\
& \#(\mathrm{~B})= \\
&=\#(\text { true baddies })+ \\
& \#(\text { false goodies })\end{aligned}$ & $\begin{array}{c}\text { Total of goodies } \\
\#(\mathrm{G})= \\
=\#(\text { true goodies })+ \\
\#(\text { false baddies })\end{array}$ & $\begin{array}{c}\text { Total number of } \\
\text { subjects in } \mathbf{T} \\
\#(\mathbf{T})\end{array}$ \\
\hline
\end{tabular}


G.Gambirasio

Correction for detector's specificity and sensitivity in contingency tables

In the following, we will write down a number of expressions about the relevant relations among the sets and among the contents. In them, we shall make use of the following property: consider a number $m>0$ and two generic sets K, L. Then, an equation between contents like $\#(\mathrm{~K})=m$.\# $(\mathrm{L})$ implies (and is implied by) the equation $\mathrm{K}=m . \mathrm{L}$ between the corresponding sets. In short, number $m$ may be freely moved across the boundary set $\leftrightarrow$ content.

From the definitions of specificity and sensitivity and from Table I:

$($ true baddies $)=(1-\gamma) . \mathrm{B}, \quad \#($ true baddies $)=(1-\gamma) . \#(\mathrm{~B})$

$($ false baddies $)=\beta . G, \quad \#($ false baddies $)=\beta . \#(\mathrm{G})$,

$($ true goodies $)=(1-\beta) . G, \quad \#($ false baddies $)=\beta . \#(G)$,

$($ false goodies $)=\gamma . \mathrm{B}, \quad \#($ false goodies $)=\gamma . \#(\mathrm{~B})$.

Pos $=($ true baddies $) \cup$ (false baddies $)$

$\mathrm{Neg}=($ true goodies $) \cup$ (false goodies $)$

$\#($ true baddies $)+\#($ false goodies $)=\#(\mathrm{~B})=\alpha . \#(\mathrm{~T})$,

$\#($ true goodies $)+\#($ false baddies $)=\#(\mathrm{G})=(1-\alpha) . \#(\mathrm{~T})$,

$\#($ false baddies $)=\beta . \#(\mathrm{G})=(1-\alpha) \cdot \beta . \#(\mathrm{~T})$,

$\#($ true goodies $)=(1-\beta) . \#(G)=(1-\alpha) .(1-\beta) . \#(T)$,

$\#($ false goodies $)=\gamma . \#(B)=\alpha . \gamma . \#(T)$,

$\#($ true baddies $)=(1-\gamma) . \#(B)=\alpha .(1-\gamma) . \#(T)$,

$\#(\operatorname{Pos})=\#($ true baddies $)+\#($ false baddies $)=(1-\gamma) . \#(\mathrm{~B})+\beta . \#(\mathrm{G})=$ $=[\alpha \cdot(1-\gamma)+(1-\alpha) \cdot \beta] . \#(T)$,

$\#(\mathrm{Neg})=\#($ true goodies $)+\#($ false goodies $)=(1-\beta) . \#(\mathrm{G})+\gamma \cdot[\#(\mathrm{~T})-\#(\mathrm{G})]=$ $=[(1-\alpha) \cdot(1-\beta)+\alpha \cdot \gamma] . \#(T)$,

$\#(\mathrm{Pos})+\#(\mathrm{Neg})=\#(\mathrm{~T})$.

Figure 1 and Table I show that an imperfect detector does not catch all the baddies, but the fraction \#(B $\cap$ Pos) of \#(B) only, that is, what is called the true baddies. The other fraction $\#(\mathrm{G} \cap \mathrm{Pos})$ is made up by goodies, that is, false baddies (or false positives). A corresponding thing happens with set Neg.

\section{A CORRECTIVE METHODOLOGY}

\section{Basic relations}

Purpose of this paper is to study how a careful operator may correct the results deriving from the use of an imperfect detector. Depending on context, correction may result to be partial or total.

The operator, besides receiving the values of \#(Pos) and \#(Neg) from the detector, must also know the sensitivity and the specificity (or $\gamma$ and $\beta$ ).

From the expressions already written we choose $\#(\operatorname{Pos})=\#($ true baddies $)+\#($ false baddies $)=$ $(1-\gamma) . \#(B)+\beta \cdot[\#(T)-\#(B)]$, then

$$
\#(\mathbf{B})=[\#(\mathbf{P o s})-\beta . \#(\mathbf{T})] /(1-\beta-\gamma)
$$


G.Gambirasio

Correction for detector's specificity and sensitivity in contingency tables

Equation (1) is important and stays at the base of the correcting methodology.

With similar procedure, Equation (2) is derived:

$$
\#(\mathbf{G})=[\#(\mathbf{N e g})-\gamma . \#(\mathbf{T})] /(1-\beta-\gamma) \text {. }
$$

Once \#(B) is computed, may the careful operator behave as if the detector had been perfect? It depends. The issue is discussed on the following.

\section{Not magic}

Once the characteristics $(\beta, \gamma)$ are known, Equation (1) may extract the total number of baddies \#(B) from \#(Pos). Is this magic? Well, no. Let us comment on the topic.

A perfect detector not only informs you about how many baddies are detected but also who they are. You can put them in a room, physically separated from the goodies in a different room. A careful operator making use of the methodology described above gets the total number \#(B) of baddies, but not who they are. Baddies are divided between set Pos and set Neg. You can even compute how many true baddies are in set Pos and how many false goodies are in set Neg, but you do not know who they are, therefore you cannot separate them in different rooms.

This is a limitation of the methodology described in this paper, the same limitation found in the probabilistic approach, as abundantly described in the literature.

So far, there seem to be no advantage in opting for a deterministic approach instead of the traditional probabilistic approach. But the deterministic approach shows its usefulness in the fact that it allows the total number (like \#(B)) of subjects in a set to be known exactly, and this is essential in contingency tables analysis. Therefore, the deterministic approach offers a complete correction from detector's imperfections in table analysis, as it is shown on the final part of this paper.

In spite of repeating some known results, this first part of this paper represents an extended introduction to the topic and should be useful for the reader to become familiar with the deterministic approach. Besides, many important relationships and equations are derived here.

\section{Proportions}

Set $\mathrm{B}$ contains true baddies and false goodies; the number of true baddies is given by the equation \#(true baddies) $=(1-\gamma)$.\#(B). Set Pos contains both true baddies and false baddies. The proportion of true baddies in set Pos is given by

$$
\text { P(true baddies } \mid \text { Pos })=(1-\gamma) . \#(B) / \#(\text { Pos }) \text {. }
$$

According to a probabilistic model this proportion (called "Positive predicting value") would represent the probability that a subject, when classified as positive, is truly belonging to the baddies. 
G.Gambirasio

Correction for detector's specificity and sensitivity in contingency tables

By a similar reasoning, the proportion of true goodies in set Neg is given by

$$
\text { P(true goodies } \mid \mathrm{Neg})=(1 \text { - } \beta) \text {. }(\mathbf{G}) / \#(\mathrm{Neg}) \text {. }
$$

According to a probabilistic model this proportion (called "Negative predicting value") would represent the probability that a subject, when classified as negative, is certainly belonging to the goodies.

\section{A SURREALISTIC EXAMPLE I}

We present an example to make the question of how many and who are the baddies in sets B and Pos more understandable. Since perfect detectors do not exist in a real world, of necessity this example runs in an ideal, fictitious world. Then, surrealistic.

Let set $\mathrm{T}$ contain subjects whose names are known. To leave the example simple, only twelve subjects are involved.

Figure 2 shows set $\mathrm{T}$, divided into two subsets (B and $\mathrm{G}$ ) representing the baddies and the goodies, respectively. Sets $B$ and $G$ contain six subjects each, therefore $\#(B)=\#(G)=6$ and $\#(T)=12$. All the twelve subjects are given personal names in order to make it possible to track them all the time.

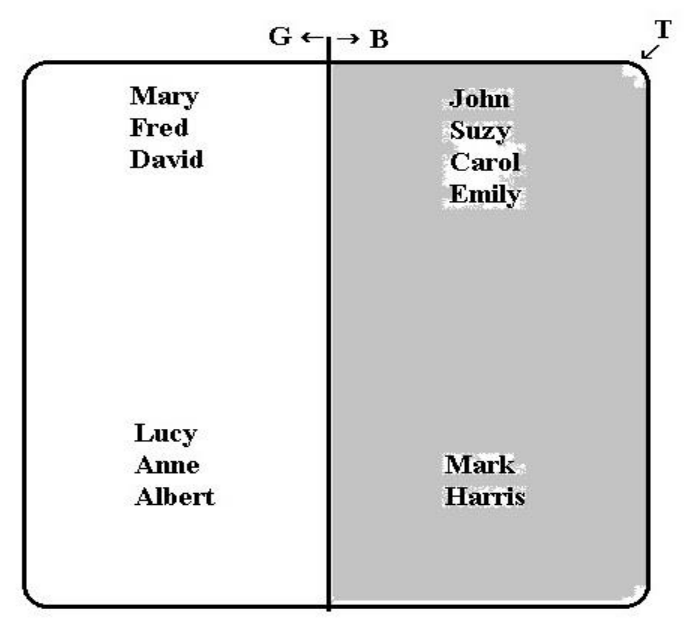

Fig. 2 - Set T, whose twelve members are named, is divided into baddies B and goodies G. A perfect detector would identify the baddies (grayed area).

So, set B $=\{$ John, Suzy, Carol, Emily, Mark, Harris $\}$ and set G $=\{$ Mary, Fred, David, Lucy, Anne, Albert . And set T obviously is the union of B and G.

We also have another character at our disposal in this example: a being who always knows everything about our subjects. We call this being the Übermensch. The Übermensch is something similar to the omniscient narrator in novels and fiction. Besides its super-human qualities, the Übermensch also owns a absolutely perfect detector to help.

In the grayed area of Figure 2 it is shown that the Übermensch, with help of the perfect detector, has identified all baddies in $\mathrm{T}$. 
Then, an imperfect detector comes along. Figure 3 shows what it sees and what information it delivers to the operators. The grayed area represents set Pos. The information about sets B and $\mathrm{G}$ is now lost, replaced by Pos $=\{$ Mary, Fred, David, John, Suzy, Carol, Emily $)$, and Neg $=$ \{Lucy, Anne, Albert, Mark, Harris .

It is therefore known that $\#(\mathrm{Pos})=7$ and $\#(\mathrm{Neg})=5$, but Pos contains both baddies and goodies, and so does Neg.

Fortunately, here comes the Übermensch! Results of its vision are pictured on Figure 4. Please observe that the Übermensch sees everything, either sets B and G, and sets Pos and Neg, all at the same time.

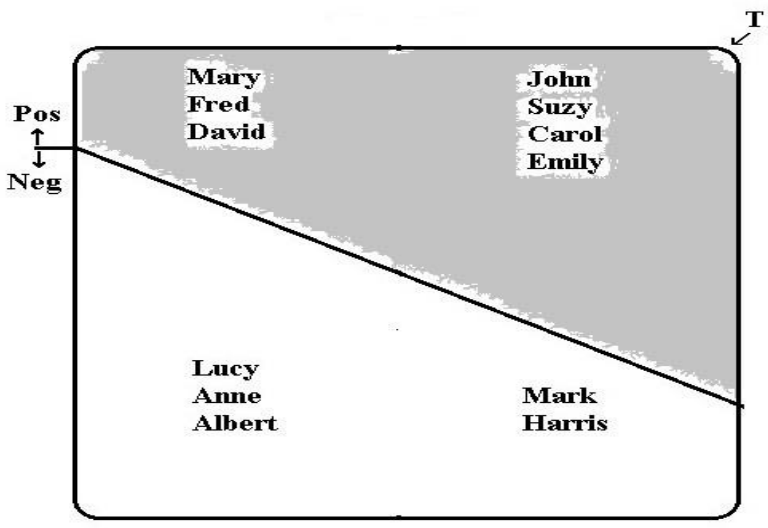

Fig. 3 - Set T, as seen by the imperfect detector, appears divided into sets Pos and $\mathrm{Neg}$, both sets mixing baddies with goodies. Distinction of B from $\mathrm{G}$ is now lost.

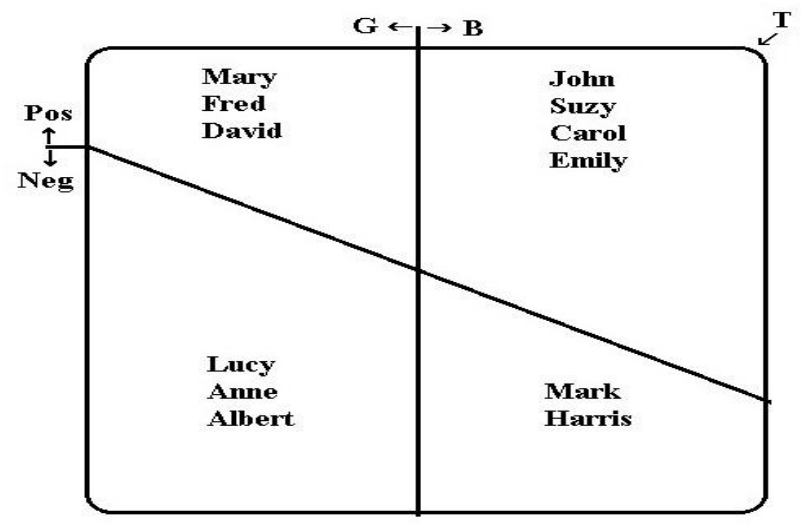

Fig. 4 - The Übermensch sees the work done by the imperfect detector, and by the perfect detector as well. 
G.Gambirasio

Correction for detector's specificity and sensitivity in contingency tables

Therefore, the Übermensch is able to find the characteristics $(\beta, \gamma)$ of the imperfect detector, as follows:

From Figure 1 and Figure 4:

specificity $=($ true goodies $) /($ total goodies $)=$

$=\#\{$ Lucy, Anne, Albert $\} / \#\{$ Mary, Fred, David, Lucy, Anne, Albert $\}=1 / 2$;

$\beta=1-$ specificity $=1 / 2$;

sensitivity $=($ true baddies $) /($ total baddies $)=$

$=\#\{$ John, Suzy, Carol, Emily $\} / \#\{$ John, Suzy, Carol, Emily, Mark, Harris $\}=2 / 3$;

$\gamma=1-$ sensitivity $=1 / 3$.

The Übermensch lets characteristics $(\beta, \gamma)$ be known to operators.

At this point, the careful operator has all it is needed to perform the correcting methodology. By using Equation (1), the operator computes \#(B):

$\#(B)=[\#(\operatorname{Pos})-\beta . \#(T)] /(1-\beta-\gamma)=[7-(1 / 2) .12] /(1-1 / 2-1 / 3)=6$

This computed \#(B) has the same value as the \#(B) found by the perfect detector, but not the same subjects. Computed B is a subset of Pos, with six unknown members.

To be specific:

a) as found by perfect detector: B $=\{$ John, Suzy, Carol, Emily, Mark, Harris $\}$;

b) as computed by careful operator: B $\subset\{$ John, Suzy, Carol, Emily, Mark, Fred, David $\}$.

However, with regard to the contents:

$\#(B$ as found by perfect detector $)=\#(B$ as computed by Equation $(1))=6$ subjects.

The proportion of true baddies in set Pos is given by Equation (3):

$\mathrm{P}($ true baddies $\mid \mathrm{Pos})=(1-\gamma) . \#(\mathrm{~B}) / \#(\mathrm{Pos})=(2 / 3) .6 / 7=4 / 7$.

The operator can put all the seven subjects of set Pos $=\{$ Mary, Fred, David, John, Suzy, Carol, Emily $\}$ in a room and tell them that four of them are baddies, but it is not known which ones.

The proportion of true goodies in set Neg is given by Equation (4):

$\mathrm{P}($ true goodies $\mid \mathrm{Neg})=(1-\beta) . \#(\mathrm{G}) / \#(\mathrm{Neg})=(1 / 2) .6 / 5=3 / 5$.

The operator can put all the five subjects of set Neg $=\{$ Lucy, Anne, Albert, Mark, Harris $\}$ in a room and tell them that three of them are goodies, but it is not known which ones.

We conclude:

1) if the purpose of the screening is to identify all the baddies/goodies (who the are), then use of Equation (1) only gives a partial correction.

2) if the purpose of the screening is to quantify the baddies/goodies (how many there are), then use of Equation (1) gives a total correction.

And what about the uncareful operator? The uncareful operator takes set Pos as it were B, and set Neg as it were G. Then, the operator simply tells the seven subjects of Pos that they are all baddies, and the five subjects of Neg that the are all goodies. That's it. 
G.Gambirasio

Correction for detector's specificity and sensitivity in contingency tables

$10 / 26$

\section{REALISTIC EXAMPLE: SCREENING FOR CANCER}

In the following example the corrective methodology will be used in a case of screening for cancer. Popular cancer detectors are mammography, Papanicolau smear, and PSA. Typical values of their characteristics are $\beta=0.15$ and $\gamma=0.1$, and the example will be built around such values.

A sample of $\#(T)=10,000$ women, submitted to a mammography screening test, gave the following results: $\#(\operatorname{Pos})=1575$ women, $\#(\mathrm{Neg})=8425$ women. These data and results from computations are shown on Table II. Three cases are considered:

1) the ideal case of a perfect detector;

2) a careful operator using an imperfect detector of known specificity and sensitivity, and following this methodology;

3) a careless operator using an imperfect detector and not following this methodology.

A perfect detector delivers the results shown on the second column of Table II. The 100 women with cancer may be identified and physically set apart from the 9900 women without cancer. This is an ideal case, the detector is hypothetical, fictitious, and the results are here for reference and comparison only.

The careful operator starts by computing \#(B):

$$
\#(B)=[\#(\operatorname{Pos})-\beta . \#(T)] /(1-\beta-\gamma)=100 \text { women. }
$$

Value of \#(B) is a property of the sample: there are really 100 women with cancer among the 10,000 women of set $\mathrm{T}$, as the perfect detector shows.

The operator then computes other properties of the sample by using the equations already shown. The third column in Table II summarizes what the careful operator has computed.

The proportion of women with cancer in Pos is an important result, because a woman which has been classified as positive may get a better idea of how much in peril she is to really have cancer: $\mathrm{P}($ true baddies $\mid \mathrm{Pos})=5.7 \%$ in this example.

And women classified as negative may better evaluate their freedom from cancer: $\mathrm{P}($ true goodies $\mid \mathrm{Neg})=\sim 100 \%$ in this example.

Let us now go to the careless operator, the operator who thinks that the content of set Pos is totally composed of baddies and the content of set Neg totally of goodies (last column in Table 2). This operator thinks that 1575 women are truly with cancer! Imagine the shock of these poor women upon receiving such news, when, with the use of a corrective methodology, each one of them only has an estimated probability around 5-6\% (in this example) of actually suffering from the disease. 
G.Gambirasio

Correction for detector's specificity and sensitivity in contingency tables

$11 / 26$

Table II - Results from different detectors and operators in cancer screening by mammography

$(\#(T)=10,000 ; \beta=0.15 ; \gamma=0.1)$

\begin{tabular}{|c|c|c|c|}
\hline $\begin{array}{c}\text { Detector/Operator } \rightarrow \\
\text { Results } \downarrow\end{array}$ & $\begin{array}{c}\text { A perfect } \\
\text { detector }\end{array}$ & $\begin{array}{l}\text { A careful operator } \\
\text { with an imperfect } \\
\text { detector and } \\
\text { following the } \\
\text { methodology }\end{array}$ & $\begin{array}{l}\text { A careless operator } \\
\text { with an imperfect } \\
\text { detector and not } \\
\text { following the } \\
\text { methodology }\end{array}$ \\
\hline$\#(\operatorname{Pos})$ & 100 & 1575 & 1575 \\
\hline$\#(\mathrm{Neg})$ & 9900 & 8425 & 8425 \\
\hline $\begin{array}{l}\#(B)=\text { total number } \\
\text { with cancer in } T\end{array}$ & 100 & 100 & 1575 \\
\hline $\begin{array}{l}\#(G)=\text { total number } \\
\text { without cancer in } T\end{array}$ & 9900 & 9900 & 8425 \\
\hline $\begin{array}{c}\#(\text { true baddies })= \\
\text { number with cancer in } \\
\text { Pos }\end{array}$ & 100 & 90 & 1575 \\
\hline $\begin{array}{c}\#(\text { false goodies })= \\
\text { number with cancer in } \\
\text { Neg }\end{array}$ & 0 & 10 & 0 \\
\hline $\begin{array}{c}\#(\text { true goodies })= \\
\text { number without cancer } \\
\text { in Neg }\end{array}$ & 9900 & 8415 & 8425 \\
\hline $\begin{array}{c}\#(\text { false baddies })= \\
\text { number without cancer } \\
\text { in Pos }\end{array}$ & 0 & 1485 & 0 \\
\hline $\begin{array}{c}\alpha=\#(\mathrm{~B}) / \#(\mathrm{~T})= \\
\text { proportion of women } \\
\text { with cancer in set } \mathrm{T}\end{array}$ & 0.01 & 0.01 & 0.1575 \\
\hline $\begin{array}{l}\mathrm{P}(\text { true baddies } \mid \mathrm{Pos})= \\
\text { proportion of women } \\
\text { with cancer in Pos }\end{array}$ & $\begin{array}{c}1 \\
(100 \%)\end{array}$ & $\begin{array}{c}0.057 \\
(5.7 \%)\end{array}$ & $\begin{array}{c}1 \\
(100 \%)\end{array}$ \\
\hline $\begin{array}{c}\mathrm{P}(\text { true goodies } \mid \mathrm{Neg})= \\
=\text { proportion of women } \\
\text { without cancer in Neg }\end{array}$ & $\begin{array}{c}1 \\
(100 \%)\end{array}$ & $\begin{array}{c}\sim 1 \\
(\sim 100 \%)\end{array}$ & $\begin{array}{c}1 \\
(100 \%)\end{array}$ \\
\hline
\end{tabular}

\section{THE NEEDLE IN THE HAYSTACK.}

Equation (3) is useful to investigate the case of very few baddies in set $\mathrm{T}$, that is, when an infected subject is a rare event in the population. A rare event (like the proverbial needle in a big haystack) means a very small value of prevalence $\alpha$ and requires a very good detector (that is, with very small values of $\beta$ and $\gamma$ ). 
G.Gambirasio

Correction for detector's specificity and sensitivity in contingency tables

Calculating the proportion

$$
\text { P(true baddies } \mid \text { Pos })=(1-\gamma) . \#(B) / \#(\text { Pos })=(1-\gamma) . \alpha /[\alpha .(1-\beta-\gamma)+\beta]
$$

appears to be a suitable way to evaluate the adequacy of detector. We name it the "performance index of a detector". Consider an experiment aimed to detect HIV. A detector like ELISA typically has parameters $\beta=10^{-4}$ and $\gamma=10^{-3}$. When the subjects come from a low-risk population, it is appropriate to take $\alpha=10^{-4}$ (one infected subject in ten thousand subjects).In such a case $\mathrm{P}$ (true baddies $\mid$ Pos) equals 0.5. This means that one half of the subjects in set Pos are infected. If $\#(T)=10,000$ subjects, then $\#(P o s)=[\alpha .(1-\gamma)+(1-\alpha) . \beta] . \#(T) \cong 2$ subjects, one of them infected and the other is healthy. (But it is not known which one is which!)

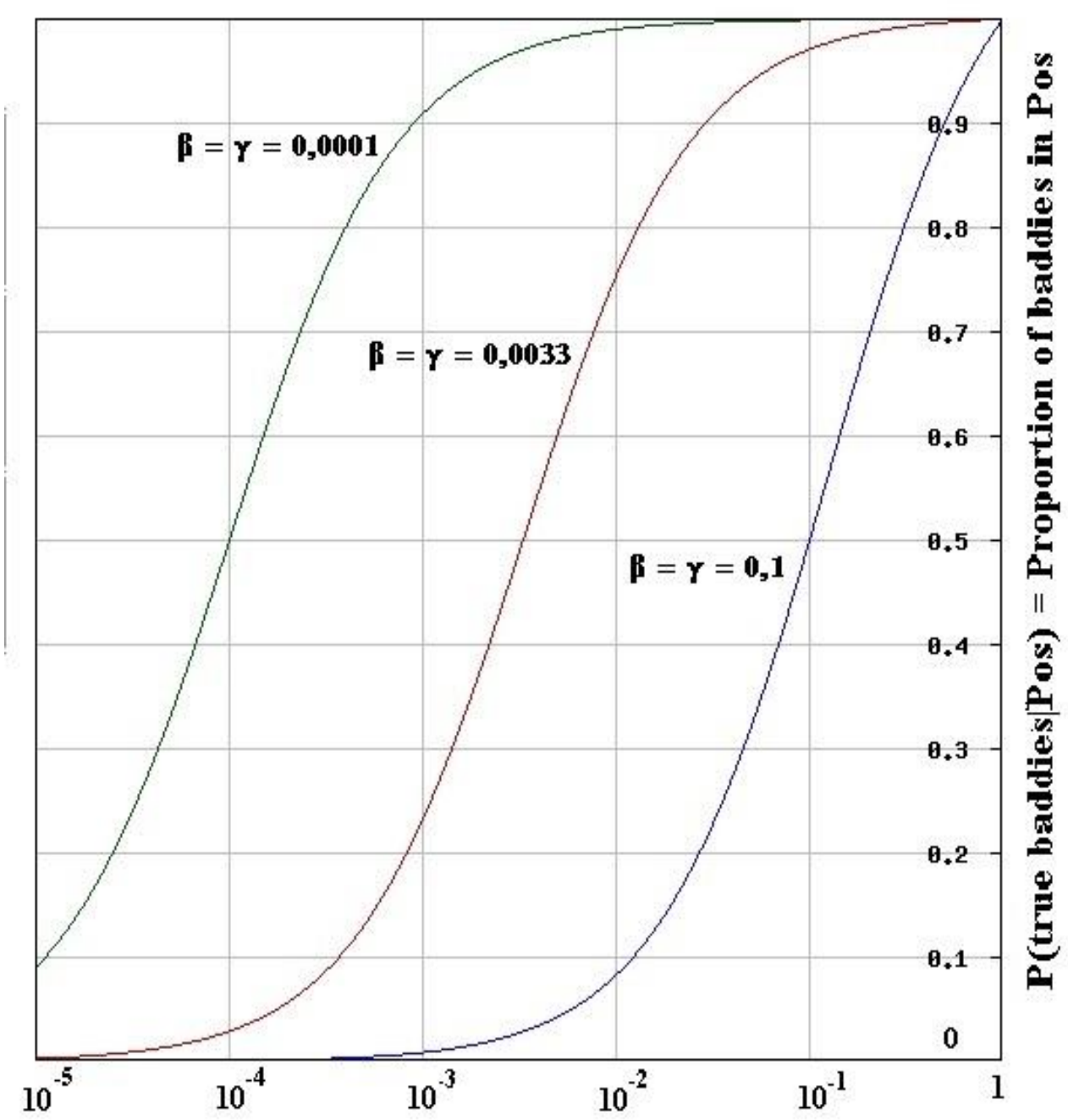

Log scale of $\alpha=\#(B) / \#(T)$

Figure 5 - Performance index when parameters are very small 
G.Gambirasio

Correction for detector's specificity and sensitivity in contingency tables

$13 / 26$

In the special case of $\alpha=\beta=\gamma \ll<1$, the performance index equals 0.5 . This means that when $\alpha, \beta$, and $\gamma$ are of the same order of magnitude (or, of smallness) it is likely to expect a performance index around 0.5 .

When all parameters are very small, in order to improve the performance index up to 0.9 one has to improve detector's $\beta$ and $\gamma$ one order of magnitude above $\alpha$.

For example, when $\alpha=10^{-3}, \beta$ and $\gamma$ must go to $10^{-4}$ in order to get an index of 0.9.

Figure 5 gives an overall view of performance index when $\alpha$ is very small, plotted for three different values of $\beta=\gamma$.

\section{CONTINGENCY TABLES AND IMPEFECT DETECTORS}

\section{Experiments and detectors}

We now arrive at the main part of this paper. As an example of what we propose to do, consider the following situation, common in health sciences: in order to study the possible influence of a drug on a certain disease, an experiment is performed, in which a group of persons (the subjects of the experiment) is examined by a detector to separate all the subjects into positives (set Pos, disease detected) and negatives (set Neg, disease not detected). At the same time, the subjects are also separated by activity: those taking the drug (set A, of active subjects) and those not taking the drug (set I, of inactive subjects). Results are written in a $2 \times 2$ contingency table. If the detector were perfect, set Pos would contain all infected subjects (the baddies, in the terminology introduced here), and set Neg all healthy subjects (the goodies). In a probabilistic approach, standard procedures are available in the literature to analyze the contingency table. Pearson's chi-square $\left(\chi^{2}\right)$ test is usually applied, informing about the probability of dependence/independence between disease and drug taking.

So far, nothing of this is new. But what happens when the detector, being a real detector, turns out being imperfect? Is it reasonable to suspect that the imperfection could adversely affect the conclusions obtained through conventional analysis of a contingency table when it is served by an imperfect detector? Could a real dependence between disease and drug be ignored, or masked, or erroneously suggested? Would performing a chi-square test still have a meaning and be valid? Is it possible to develop a methodology capable of minimizing or entirely avoiding the damage of imperfections, when specificity and sensitivity are known?

All these questions will be addressed to in the following. The analysis will be based on two previous studies:

1) paper $\left({ }^{1}\right)$ "A deterministic approach to contingency tables analysis" (DOI 10.31219/osf.io/s94zr.) which explains the deterministic approach and also contains a numerical example to be further used here.

2) the study of imperfect detectors presented at the beginning of this paper.

In all cases, it is supposed that the information about subjects' activity/inactivity is always correct. Activity (like taking a certain drug) is always chosen here to be the supposed cause, and state of disease the corresponding effect. 
G.Gambirasio

Correction for detector's specificity and sensitivity in contingency tables

According to the deterministic approach $\left({ }^{1}\right)$, subjects are considered to be members of sets, whose contents are displayed on a $2 \times 2$ contingency table.

Figure 6(a) shows sets $\mathrm{T}$ and $\mathrm{A}$ as seen by a perfect detector, and Figure 6(b) by an imperfect detector. Based on these figures, the respective contingency tables may be built. Grayed areas represent the content of respective cell $\mathrm{C}_{11}$ in the tables, that is, $\mathrm{B} \cap \mathrm{A}$ or $\operatorname{Pos} \cap \mathrm{A}$.

A contingency table in the traditional form only shows the results of one experiment, that is, one in which all four cells are given fixed values, reflecting the results of that specific experiment. But, as it has been done in $\left({ }^{1}\right)$, we wish more, we wish to cover a full range of experiments, obviously all compatible with the same marginal values and the same detector.

Since these tables only have one degree of freedom, it is sufficient to specify one cell. For this, we always choose the first cell $\mathrm{C}_{11}$. By choosing the variables $x=\#(\mathrm{~B} \cap \mathrm{A})$ and $y=\#(\operatorname{Pos} \cap \mathrm{A})$, a range of cases, and not only a specific one, may be covered.

Figure 6 (a) shows how a perfect detector would see sets T and A. Table III is the corresponding contingency table. Table shows variable $x$, used to represent cell $\mathrm{C}_{11}$ in different situations as it goes over all permitted values.

Presence of a perfect detector is useful as its results are term of comparison and a goal to be reached by a corrective methodology. This detector, however, is only fictitious, without real existence. Figure 6 (b) shows how a real, imperfect detector sees sets T and A. Table IV is the corresponding contingency table, with $y$ the running variable. Results from this detector must be corrected by an appropriate methodology, our object of research.

In a given experiment the contents of sets T, A, I, B, G are fixed, because they are characteristics of the sample. They do not change if a different detector, with different $\beta$ and $\gamma$, is used. The contents of sets Pos and Neg, however, depend upon $\beta$ and $\gamma$, and change when these parameters change.

In contingency tables, cells' contents are related to marginal values by the following expressions:

$$
\begin{aligned}
& \#(\operatorname{Pos})=\#(\operatorname{Pos} \cap A)+\#(\operatorname{Pos} \cap I) ; \\
& \#(N e g)=\#(\operatorname{Neg} \cap A)+\#(\operatorname{Neg} \cap I) ; \\
& \#(A)=\#(\operatorname{Pos} \cap A)+\#(\operatorname{Neg} \cap A) ; \\
& \#(I)=\#(\operatorname{Pos} \cap I)+\#(\operatorname{Neg} \cap I) ; \\
& \#(P o s)+\#(N e g)=\#(A)+\#(I)=\#(T)
\end{aligned}
$$




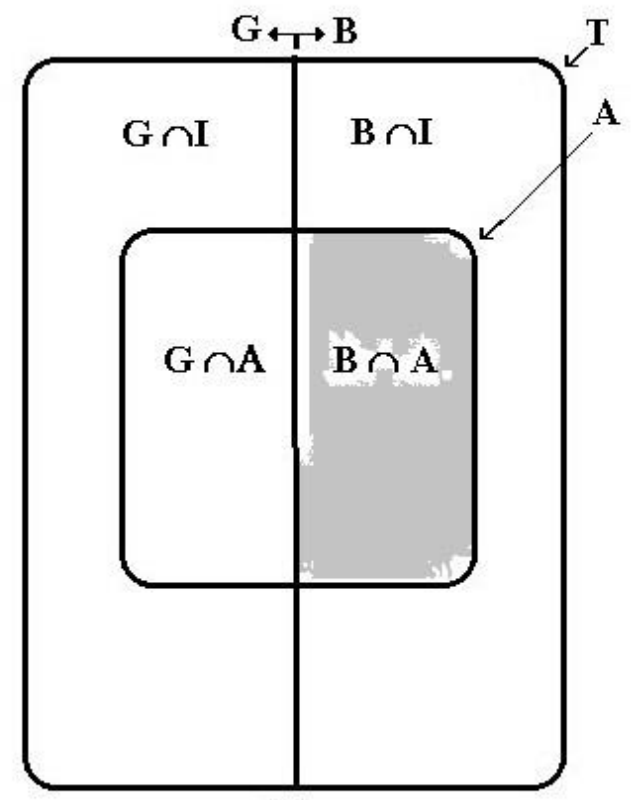

(a)

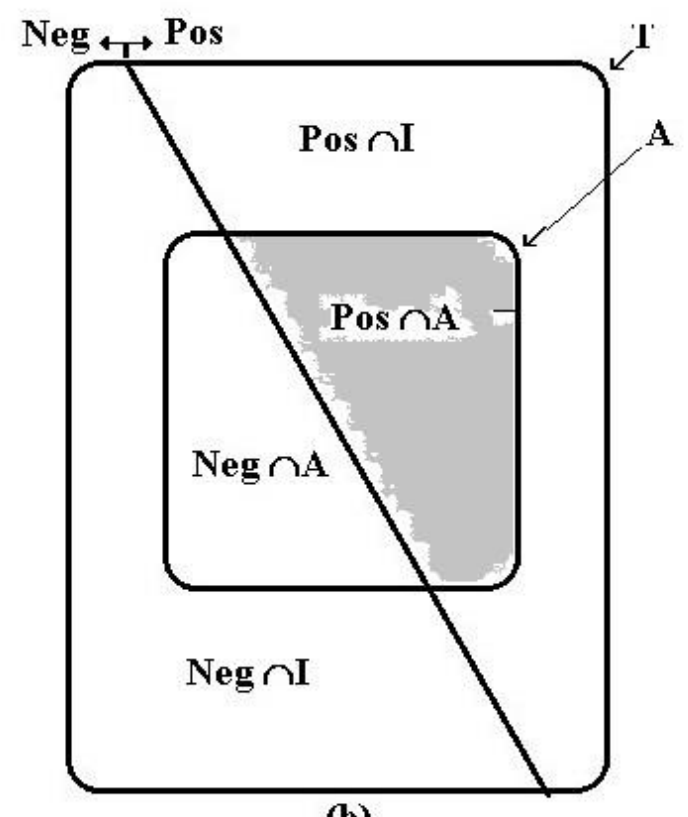

(b)

Figure 6 - A perfect detector sees sets T and A as shown in (a), and an imperfect detector sees the same sets in (b). Grayed areas represent the content of cell $\mathrm{C}_{11}$ in the respective contingency tables.

Table III - Relations among sets and their contents, shown in a contingency table served by a perfect detector, expressed as functions of variable $x=\#(B \cap A)$

\begin{tabular}{|c|c|c|c|}
\hline $\begin{array}{c}\text { Effect } \rightarrow \\
\text { Cause } \downarrow\end{array}$ & Subjects in set B & Subjects in set G & Totals \\
\hline $\begin{array}{c}\text { Active subjects } \\
\text { A }\end{array}$ & $\begin{array}{c}\mathrm{C}_{11}=\#(\mathrm{~B} \cap \mathrm{A})=x \\
x_{\min } \leq x \leq x_{\max }\end{array}$ & $\begin{array}{c}\mathrm{C}_{12}=\#(\mathrm{G} \cap \mathrm{A})=\#(\mathrm{~A})-x \\
=\end{array}$ & $\begin{array}{c}\text { Total number of } \\
\text { active subjects } \\
\#(\mathrm{~A})\end{array}$ \\
\hline $\begin{array}{c}\text { Inactive subjects } \\
\text { I }\end{array}$ & $\begin{array}{c}\mathrm{C}_{21}=\#(\mathrm{~B} \cap \mathrm{I})= \\
=\#(\mathrm{~B})-x\end{array}$ & $\begin{array}{c}\mathrm{C}_{22}=\#(\mathrm{G} \cap \mathrm{I})= \\
=\#(\mathrm{I})+x-\#(\mathrm{~B})= \\
=\#(\mathrm{G})+x-\#(\mathrm{~A})\end{array}$ & $\begin{array}{c}\text { Total number of } \\
\text { inactive subjects } \\
\#(\mathrm{I})\end{array}$ \\
\hline Totals & $\begin{array}{c}\#(\mathrm{~B})=\text { total number } \\
\text { of baddies in set } \mathrm{T}\end{array}$ & $\begin{array}{c}\#(\mathrm{G})=\text { total number } \\
\text { of goodies in set T }\end{array}$ & $\begin{array}{c}\text { Total number of } \\
\text { subjects \#(T) }\end{array}$ \\
\hline
\end{tabular}


G.Gambirasio

Correction for detector's specificity and sensitivity in contingency tables

Table IV- Relations among sets and their contents, shown in a contingency table served by an imperfect detector, expressed as functions of variable $y=\#(\operatorname{Pos} \cap A)$

\begin{tabular}{|c|c|c|c|}
\hline $\begin{array}{c}\text { Effect } \rightarrow \\
\text { Cause } \downarrow\end{array}$ & Subjects in set Pos & Subjects in set Neg & Totals \\
\hline $\begin{array}{c}\text { Active subjects } \\
\text { A }\end{array}$ & $\begin{array}{c}\mathrm{C}_{11}=\#(\operatorname{Pos} \cap \mathrm{A})= \\
=y \\
y_{\min } \leq y \leq y_{\max }\end{array}$ & $\begin{array}{c}\mathrm{C}_{12}=\#(\mathrm{Neg} \cap \mathrm{A})= \\
=\#(\mathrm{~A})-y\end{array}$ & $\begin{array}{c}\text { Total number of } \\
\text { active subjects \#(A) }\end{array}$ \\
\hline $\begin{array}{c}\text { Inactive subjects } \\
\text { I }\end{array}$ & $\begin{array}{c}\mathrm{C}_{21}=\#(\mathrm{Pos} \cap \mathrm{I})= \\
=\#(\mathrm{Pos})-y\end{array}$ & $\begin{array}{c}\mathrm{C}_{22}=\#(\mathrm{Neg} \cap \mathrm{I})= \\
=\#(\mathrm{I})-\#(\mathrm{Pos})+y\end{array}$ & $\begin{array}{c}\text { Total number of } \\
\text { inactive subjects \#(I) }\end{array}$ \\
\hline Totals & $\begin{array}{c}\#(\text { Pos })=\text { total } \\
\text { number of positive } \\
\text { subjects in set T }\end{array}$ & $\begin{array}{c}\#(\mathrm{Neg})=\text { total } \\
\text { number of negative } \\
\text { subjects in set T }\end{array}$ & $\begin{array}{c}\text { Total number of } \\
\text { subjects \#(T) }\end{array}$ \\
\hline
\end{tabular}

\section{Developing the methodology}

An important result toward building the methodology comes from Equation (1), rewritten here: $\#(\mathbf{B})=[\#(\mathbf{P o s})-\beta . \#(\mathbf{T})] /(\mathbf{1}-\boldsymbol{\beta}-\boldsymbol{\gamma})$.

This equation gives the total number of baddies contained in set $\mathrm{T}$. It does not give the whole set $B$ (that is, a listing of all the subjects that are baddies), only the content \#(B) (that is, the number of such subjects). This distinction is important, it was discussed earlier, and will be discussed further.

After having related \#(B) to \#(Pos), in order to complete the corrective methodology it is necessary to relate $\#(B \cap A)$ to $\#(\operatorname{Pos} \cap A)$ or, more simply, variable $x$ to variable $y$.

Since sets $B$ and $G$ are disjoint sets, then from the content equation $\#(\operatorname{Pos})=(1-\gamma)$. $(B)+$ $\beta$.\#(G) we write the corresponding set equation $\operatorname{Pos}=(1-\gamma)$. B $\cup \beta$.G. The intersection with set $A$ is: $P$ os $\cap A=[(1-\gamma) . B \cap A] \cup[\beta . G \cap A]$.

Then, back again to contents: $\#(\operatorname{Pos} \cap A)=(1-\gamma) . \#(B \cap A)+\beta . \#(G \cap A)$.

From Table III and Table IV it is possible to write $y=(1-\gamma) \cdot x+\beta .(\#(\mathrm{~A})-x)$. Finally:

$$
\begin{gathered}
\#(\operatorname{Pos} \cap A)=y=(1-\beta-\gamma) \cdot x+\beta . \#(A), \\
\#(B \cap A)=x=[y-\beta . \#(A)] /(1-\beta-\gamma) .
\end{gathered}
$$

Equation (1) and Equation (6) together complete the desired "corrective methodology". A careful operator will employ these equations to write the corrected contingency table. This "corrected" table happens to be identical to Table III, exactly the table a perfect detector would produce (and this is why we do not print it here, it would only be a copy of that table!) 
G.Gambirasio

Correction for detector's specificity and sensitivity in contingency tables

$17 / 26$

\section{Allowed range of $x$ and $y$}

As it is shown on contingency tables, variables $x$ and $y$ are constrained to take values between limits. The limits are chosen as not to break any compatibility rule within the structure of a table. This matter is studied in paper $\left({ }^{1}\right)$, and the results are shown here. We shall start with variable $x$.

Let $x^{*}$ be the value of $x$ that certainly stays within the possible range. Compatibility with marginal values is assured by checking the following expressions:

a) it must be true that $0 \leq \mathrm{P}(\mathrm{B} \mid \mathrm{A})=\#(\mathrm{~B} \cap \mathrm{A}) / \#(\mathrm{~A}) \leq 1$, then $0 \leq x^{*} \leq \#(\mathrm{~A})$;

b) it must also be true that $0 \leq \mathrm{P}(\mathrm{B} \mid \mathrm{I})=\#(\mathrm{~B} \cap \mathrm{I}) / \#(\mathrm{I}) \leq 1$, then $\mathrm{B} \geq x^{*} \geq \#(\mathrm{~B})-\#(\mathrm{I})$.

The interval satisfying both the above inequalities is the allowed range of $x$.

A simpler, more practical rule is the following:

a) if $\#(A)+\#(B) \leq \#(T)$, then $x_{\min }=0$;

b) if $\#(\mathrm{~A})+\#(\mathrm{~B})>\#(\mathrm{~T})$, then $x_{\min }=\#(\mathrm{~A})+\#(\mathrm{~B})-\#(\mathrm{~T})$.

As for $x_{\max }$, it always is the lesser one of values \#(A) and \#(B):

$x_{\max }=\min [\#(\mathrm{~B}), \#(\mathrm{~A})]$.

Regarding variable $y=\#(\operatorname{Pos} \cap A)$, we shall make use of Equation (5) to get the corresponding limits:

a) if $\#(\mathrm{~A})+\#(\mathrm{~B}) \leq \#(\mathrm{~T})$, then $y_{\min }=\beta$. $\#(\mathrm{~A})$;

b) if $\#(A)+\#(B)>\#(T)$, then $y_{\min }=(1-\beta-\gamma) \cdot[\#(A)+\#(B)-\#(T)]+\beta . \#(A)$.

And:

$y_{\max }=(1-\beta-\gamma) \cdot \min [\#(B), \#(A)]+\beta . \#(A)$.

\section{Evaluation of dependence/independence}

Dependence evaluator $\left({ }^{1}\right)$ measures how strongly the effect is associated with the supposed cause (like, how strongly a disease status is influenced by taking a certain drug).

The particular cases of $x$ or $y$ at which activity A (like, taking the drug) does not seem to produce any result on disease status are very important. Those values of $x$ or $y$ are respectively called $x_{0}$ and $y_{0}$, and also known as "independence values". Let us compute such values.

We start with the "corrected" Table III. The proportions of interest $\left({ }^{1}\right)$ are:

$\mathrm{P}(\mathrm{B} \mid \mathrm{A})=\#(\mathrm{~B} \cap \mathrm{A}) / \#(\mathrm{~A})=x / \#(\mathrm{~A})$,

$\mathrm{P}(\mathrm{B} \mid \mathrm{I})=\#(\mathrm{~B} \cap \mathrm{I}) / \#(\mathrm{I})=(\#(\mathrm{~B})-x) / \#(\mathrm{I})$.

The dependence evaluator of $\mathrm{B}$ on $\mathrm{A}$ is given $\left({ }^{1}\right)$ by:

$\operatorname{dep}(\mathrm{B} \mid \mathrm{A})=[\mathrm{P}(\mathrm{B} \mid \mathrm{A})-\mathrm{P}(\mathrm{B} \mid \mathrm{I})] /[\mathrm{P}(\mathrm{B} \mid \mathrm{A})+\mathrm{P}(\mathrm{B} \mid \mathrm{I})]=$

$=[x . \#(\mathrm{~T})-\#(\mathrm{~A}) . \#(\mathrm{~B})] /[x .(\#(\mathrm{I}) . \#(\mathrm{~B}))+\#(\mathrm{~A}) . \#(\mathrm{~B})]$ 
G.Gambirasio

Correction for detector's specificity and sensitivity in contingency tables

$18 / 26$

Evaluator $\operatorname{dep}(\mathrm{B} \mid \mathrm{A})$ is a number between -1 and +1 . The greater the absolute value of the evaluator, the stronger is the association of effect with supposed cause. A positive evaluator means that cause and effect grow in the same direction (like, intensity of smoking and lung cancer). A negative evaluator means that cause and effect grow in opposite directions (like, physical exercise and heart diseases).

If $\mathrm{P}(\mathrm{B} \mid \mathrm{A})$ equals $\mathrm{P}(\mathrm{B} \mid \mathrm{I})$, then $\operatorname{dep}(\mathrm{B} \mid \mathrm{A})=0$, meaning that the number of baddies does not depend on the subjects being active or not. This is precisely the condition of independence of effect from supposed cause (drug has no effect on illness).

The value of $x$ which corresponds to independence has already been called $x_{0}$.

Then $x_{0} / \#(\mathrm{~A})=\left(\#(\mathrm{~B})-x_{0}\right) / \#(\mathrm{I})$; after simplification:

$$
x_{0}=\#(\mathbf{B}) \text {.\#(A) / \#(T). }
$$

Independence is given by properties of the sample only and does not depend on detector's characteristics. Sets B, A and T are all property of the sample and stay untouched by detector's imperfections. As long as marginal values do not change, $x_{0}$ will not change either.

In complement to this finding, let us see what happens with the expression of $y_{0}$ corresponding to $x_{0}$. From Table IV the proportion of interest are

$\mathrm{P}(\operatorname{Pos} \mid \mathrm{A})=\#(\operatorname{Pos} \cap \mathrm{A}) / \#(\mathrm{~A})=y / \#(\mathrm{~A}) ; \quad \mathrm{P}(\operatorname{Pos} \mid \mathrm{I})=\#(\operatorname{Pos} \cap \mathrm{I}) / \#(\mathrm{I})=(\#(\operatorname{Pos})-y) / \#(\mathrm{I})$.

The dependence evaluator of Pos on $\mathrm{A}$ is given $\left(^{1}\right)$ by:

$\operatorname{dep}(\operatorname{Pos} \mid \mathrm{A})=[\mathrm{P}(\operatorname{Pos} \mid \mathrm{A})-\mathrm{P}(\operatorname{Pos} \mid \mathrm{I})] /[\mathrm{P}(\mathrm{B} \mid \mathrm{A})+\mathrm{P}(\operatorname{Pos} \mid \mathrm{I})]=$

$=[y . \#(\mathrm{~T})-\#(\mathrm{~A}) . \#(\mathrm{~B})] /[y .(\#(\mathrm{I}) . \#(\mathrm{~B}))+\#(\mathrm{~A}) . \#(\mathrm{~B})]$.

The independence value $y_{0}$ now takes the form $y_{0}=\#(\operatorname{Pos})$. $(\mathrm{A}) / \#(\mathrm{~T})$ and, through \#(Pos), it is clearly dependent on detector's characteristics. If $\beta$ or $\gamma$ changes, $y_{0}$ also change (but $x_{0}$ does not!)

Since \#(Pos) depends on detector's parameters, it changes if the detector is replaced by another one with different parameters. If that replacement occurs, the value of $y_{0}$ also changes accordingly. Therefore - and this is important - the decision on whether the effect is or is not dependent on the supposed cause itself depends on the detector that happens to have been chosen. This fact turns the experiment useless as means to ascertaining independence, unless the operator follows a correcting methodology.

\section{Comments on the methodology}

Value of \#(B), when computed by the operator through Equation (1), is exactly equal to the value given by a perfect detector. However, as it has already been commented upon, Equation (1) simply corrects \#(Pos) to \#(B), but it cannot hide the fact that set Pos only includes less than the total number of baddies in set $\mathrm{T}$. Therefore, the baddies in calculated $\mathrm{B}$ cannot be identified. 
In summary:

a) The methodology only partially corrects the influence of imperfection on calculated set B. If we only aim at identifying the baddies in calculated \#(B), the methodology fails, because computed set $\mathbf{B} \neq$ true set $\mathbf{B}$. This was the case discussed at the beginning of paper.

b) Since all values on a contingency tables are contents (numbers, not sets), then the methodology completely corrects the influence of imperfections on calculated content $\#(B)$ because computed content \#(B) = true content \#(B).

Once Table III is obtained, as above described, a careful operator may use it to perform all computations that he/she would make if Table III had been written by a perfect detector.

Specifically, evaluator $\operatorname{dep}(\mathrm{B} \mid \mathrm{A})$ may be calculated to know how strong is the association of disease status with activity. These computations are fully described in paper $\left({ }^{1}\right)$ and will not be repeated here. Adopting a probabilistic approach to Table III is now a legitimate process, including the use of chi-square test to assess the probability of dependence/independence.

On the other hand, a careless operator would, as usual, take Table IV as a good one, then certainly arrive at wrong conclusions.

\section{A SURREALISTIC EXAMPLE II}

\section{Introduction}

In order to get a better understanding of how the imperfections influence the conclusions, we will again consider the case discussed before, in section "A SURREALISTIC EXAMPLE I". In this new example, set $\mathrm{T}$ is part of an experimental test designed to verify how a treatment (action A) or lack of it (inaction I) with a certain drug may affect the baddies. Having few subjects with known names makes it easier to follow what happens to all subjects along the computations. Already computed values of $\beta=1 / 2, \gamma=1 / 3$, and $\#(B)=6$ will be used again here.

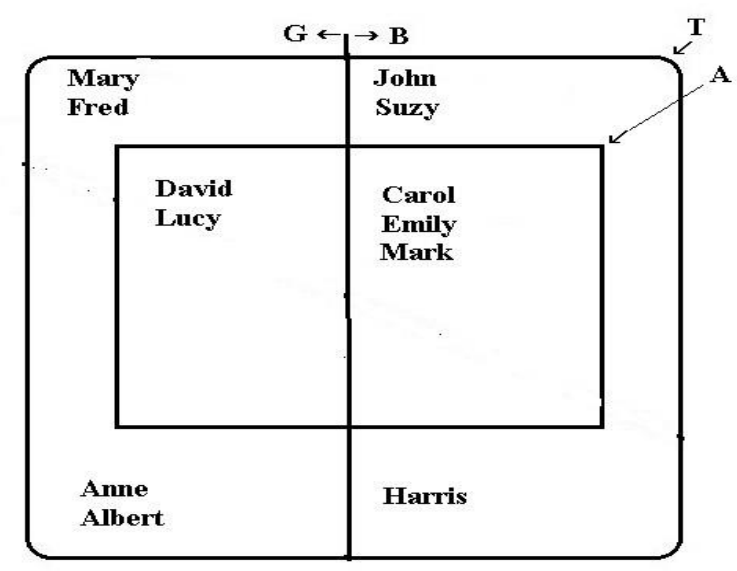

Figure 7 - The perfect detector sees how subjects in set $\mathrm{T}$ are divided among sets B, G, A, and I = not-A. 
Table V - Contingency table of experiment, as seen by the perfect detector

\begin{tabular}{|c|c|c|c|}
\hline $\begin{array}{c}\text { Effect } \rightarrow \\
\text { Cause } \downarrow\end{array}$ & Subjects in set B & Subjects in set G & Totals \\
\hline $\begin{array}{c}\text { Active subjects } \\
\text { A }\end{array}$ & $\begin{array}{c}\mathrm{C}_{11}=\#(\mathrm{~B} \cap \mathrm{A})= \\
=3\end{array}$ & $\begin{array}{c}\mathrm{C}_{12}=\#(\mathrm{G} \cap \mathrm{A})= \\
=2\end{array}$ & $\begin{array}{c}\text { Total number of } \\
\text { active subjects } \\
\#(\mathrm{~A})=5\end{array}$ \\
\hline $\begin{array}{c}\text { Inactive subjects } \\
\text { I }\end{array}$ & $\begin{array}{c}\mathrm{C}_{21}=\#(\mathrm{~B} \cap \mathrm{I})= \\
=3\end{array}$ & $\begin{array}{c}\mathrm{C}_{22}=\#(\mathrm{G} \cap \mathrm{I})= \\
=4\end{array}$ & $\begin{array}{c}\text { Total number of } \\
\text { inactive subjects } \\
\#(\mathrm{I})=7\end{array}$ \\
\hline Totals & $\begin{array}{c}\text { Total subjects } \\
\text { in set } \mathrm{B} \\
\#(\mathrm{~B})=6\end{array}$ & $\begin{array}{c}\text { Total subjects } \\
\text { in set } \mathrm{G} \\
\#(\mathrm{G})=6\end{array}$ & $\begin{array}{c}\text { Total number of } \\
\text { subjects } \\
\#(\mathbf{T})=\mathbf{1 2}\end{array}$ \\
\hline
\end{tabular}

To start, we will again ask the Übermensch to help us with its super powers and its perfect detector. Figure 7 shows what the Übermensch sees, and Table V is the corresponding contingency table, all before any imperfect detector is applied.

Table V may be used as an ordinary contingency table written with help of a perfect detector. It may be approached from the deterministic point of view or/and from the probabilistic point of view. In the following, the Übermensch will do both things.

By taking the deterministic approach, the Übermensch computes:

$\mathrm{P}(\mathrm{B} \mid \mathrm{A})=\#(\mathrm{~B} \cap \mathrm{A}) / \#(\mathrm{~A})=3 / 5$

$\mathrm{P}(\mathrm{B} \mid \mathrm{I})=\#(\mathrm{~B} \cap \mathrm{I}) / \#(\mathrm{I})=3 / 7$.

The association evaluator results:

$\operatorname{dep}(\mathrm{B} \mid \mathrm{A})=[\mathrm{P}(\mathrm{B} \mid \mathrm{A})-\mathrm{P}(\mathrm{B} \mid \mathrm{I})] /[\mathrm{P}(\mathrm{B} \mid \mathrm{A})+\mathrm{P}(\mathrm{B} \mid \mathrm{I})]=+1 / 6$.

Being positive, $\operatorname{dep}(\mathrm{B} \mid \mathrm{A})$ suggests that an increase in activity would also increase the badness.

By taking the probabilistic approach, the Übermensch wishes to assess, with a chi-square test, whether the badness could be independent of action and with what probability. For such a purpose, a contingency table corresponding to the case of independence must be written.

First, the table's value of $C_{11}$ is computed: $C_{11}=\#(B)$. $\#(A) / \#(T)=6 \times 5 / 12=2.5$.

Attention: a fractional value does not mean that some subject should be cut in half; it is only a number in a computation. With so small a number of subjects, there is always a finite chance of not getting whole numbers in some cells.

The cells in a contingency table corresponding to the case of independence then are:

$$
\begin{aligned}
& \mathrm{C}_{11}=\#(\mathrm{~B} \cap \mathrm{A})=2.5 ; \quad \mathrm{C}_{12}=\#(\mathrm{G} \cap \mathrm{A})=2.5 ; \\
& \mathrm{C}_{21}=\#(\mathrm{~B} \cap \mathrm{I})=3.5 ; \quad \mathrm{C}_{22}=\#(\mathrm{G} \cap \mathrm{I})=3.5 \text {. }
\end{aligned}
$$

The value of chi-square shall be given $\left({ }^{1}\right)$ by the equation $\chi^{2}=k \cdot\left(x-x_{0}\right)$. Let us identify all symbols:

$k=\left(1 / \mathrm{C}_{11}\right)+\left(1 / \mathrm{C}_{12}\right)+\left(1 / \mathrm{C}_{21}\right)+\left(1 / \mathrm{C}_{21}\right)+\left(1 / \mathrm{C}_{22}\right)=$

$=(1 / 2.5)+(1 / 2.5)+(1 / 3.5)+(1 / 3.5)=1.37$.

$x=3 ; x_{0}=2.5$.

Then $\chi^{2}=1.37 .(3-3.5)^{2}=0.34$, which gives a probability of independence of $p=0.56$. (The "null hypothesis" is not to be excluded; seemingly there is almost no effect of drug on baddies). 
Conclusion 1: the experiment of Table V did not convey any substantial judgment about the influence of the activity upon badness $(p=0.56)$.

Conclusion 2: we now have a standard against which we may compare the results of correction methodology.

\section{The imperfect detector}

The real test makes use of a real imperfect detector, whose characteristics $(\beta=1 / 2, \gamma=1 / 3)$

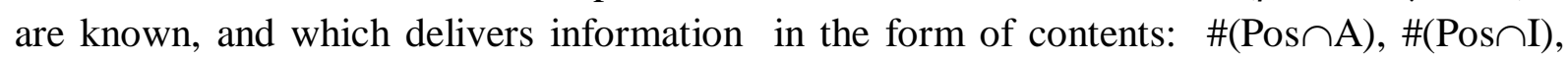
$\#(\mathrm{Neg} \cap \mathrm{A})$, and $\#(\mathrm{Neg} \cap \mathrm{I})$.

Detector's view is shown on Figure 8; grayed area is set $\mathrm{A} \cap$ Pos. And the corresponding contingency table is Table VI.

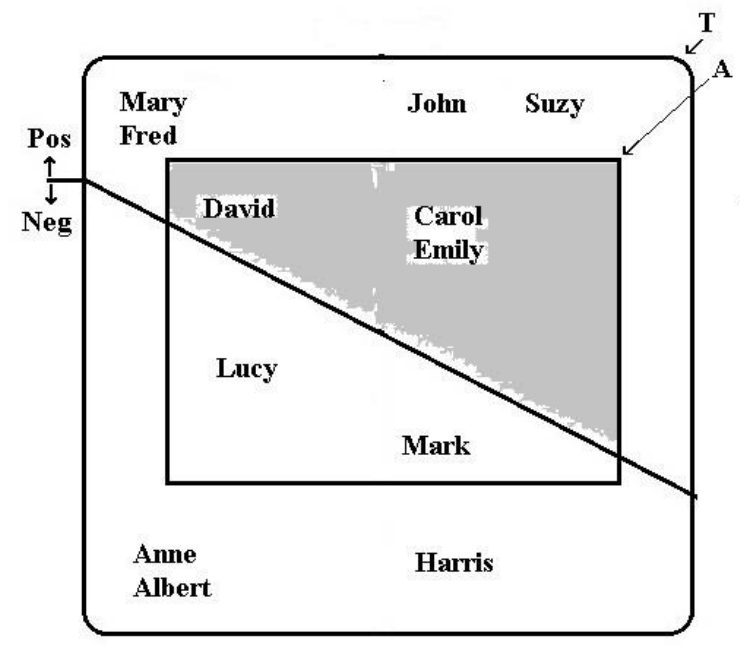

Fig. 8 - An imperfect detector is used in the experiment. Grayed area denotes set $\mathrm{A} \cap$ Pos.

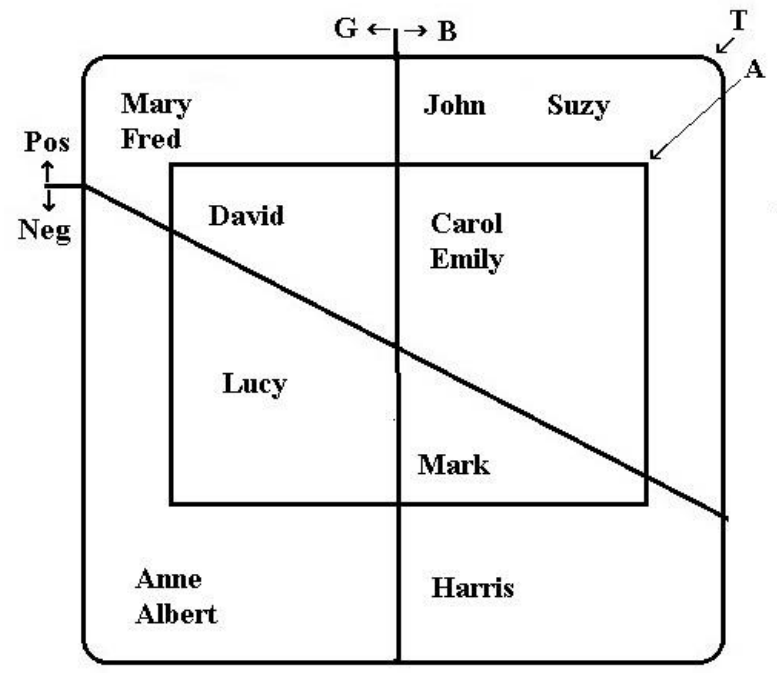

Fig. 9 - Übermensch's global view of set $\mathrm{T}$ after imperfect detector action. 
G.Gambirasio

Correction for detector's specificity and sensitivity in contingency tables

Let the Übermensch first take a look at the experiment. The Übermensch can see everything, as Figure 9 shows.

The careful operator applies Equation (1) and computes \#(B) $=6$. This computed \#(B) has the same value as \#(B) found by the perfect detector (Table V), but not the same subjects, as before noted.

The operator goes on toward writing a corrected table, using the above value of \#(B) and computing $\mathrm{C}_{11}=\#(\mathrm{~B} \cap \mathrm{A})=[\#(\operatorname{Pos} \cap \mathrm{A})-\beta . \#(\mathrm{~A})] /(1-\beta-\gamma)=[3-(1 / 2) \times 5] /(1 / 6)=3$ from Equation (6). The reader may check that the corrected table turns out to be exactly equal to the table that the perfect detector had found (Table V).

Table VI - Contingency table built with data from imperfect detector

\begin{tabular}{|c|c|c|c|}
\hline $\begin{array}{c}\text { Effect } \rightarrow \\
\text { Cause } \downarrow\end{array}$ & Subjects in set Pos & Subjects in set Neg & Totals \\
\hline $\begin{array}{c}\text { Active subjects } \\
\text { A }\end{array}$ & $\begin{array}{c}\mathrm{C}_{11}=\#(\mathrm{Pos} \cap \mathrm{A})=3 \\
=3\end{array}$ & $\begin{array}{c}\mathrm{C}_{12}=\#(\mathrm{Neg} \cap \mathrm{A})= \\
=2\end{array}$ & $\begin{array}{c}\text { Total number of } \\
\text { active subjects } \\
\#(\mathrm{~A})=5\end{array}$ \\
\hline $\begin{array}{c}\text { Inactive subjects } \\
\text { I }\end{array}$ & $\begin{array}{c}\mathrm{C}_{21}=\#(\mathrm{Pos} \cap \mathrm{I})= \\
=4\end{array}$ & $\begin{array}{c}\mathrm{C}_{22}=\#(\mathrm{Neg} \cap \mathrm{I})= \\
=3\end{array}$ & $\begin{array}{c}\text { Total number of } \\
\text { inactive subjects } \\
\#(\mathrm{I})=7\end{array}$ \\
\hline Totals & $\begin{array}{c}\text { Total subjects } \\
\text { in set Pos } \\
\#(\operatorname{Pos})=7\end{array}$ & $\begin{array}{c}\text { Total subjects } \\
\text { in set Neg } \\
(\mathrm{Neg})=5\end{array}$ & $\begin{array}{c}\text { Total number of } \\
\text { subjects } \\
\#(\mathbf{T})=\mathbf{1 2}\end{array}$ \\
\hline
\end{tabular}

Conclusion: the contingency table written by the careful operator exactly equals the table given by the perfect (and fictitious!) detector.

This fact is important. It means that a careful operator may write a contingency table by using the correction methodology here developed, and may use such table as it were given by a perfect detector. The methodology totally corrects the influence of detector's imperfections and gives the true contingency table back.

And what about the subjects belonging to set B but not to "computed B"? Let us clarify the situation by writing the corresponding sets:

True set B = \{John, Suzy, Carol, Emily, Mark, Harris $\}$; \#(true B) =6;

Computed set $B \subset\{$ John, Suzy, Carol, Emily, David, Mary, Fred $\}$; $\#$ (computed B) $=6$.

Computed set B is a set with 6 elements coming from set $\{$ John, Suzy, Carol, Emily, David, Mary, Fred $\}$. Which elements belong to computed B is not known.

\section{Then, true set $B \neq$ computed set $B$.}

But \#(true B $)=$ \#(computed B $)$.

The last equality is what matters in this case!

Numbers really matter. Defendit numerus! concluded the Übermensch. 
G.Gambirasio

Correction for detector's specificity and sensitivity in contingency tables

And the careless operator? This operator is linked with Table VI and disregards the corrective methodology. The whole table depends on detector's parameters and all conclusions will surely change if a different detector, with different parameters, is used in place. This fact turns the detector a useless device to study a possible influence of activity on disease. Unless, of course, the operator accepts to follow the corrective methodology.

\section{A WORKED EXAMPLE}

\section{Preview of output of imperfect detector in a specific case}

An example had been presented on paper $\left({ }^{1}\right)$ to show how to deal with a contingency table within the frame of a deterministic approach, but using a perfect detector. The present example will be based on that one, but extended to the case of an imperfect detector. We know the following about the original example:

$\#(B)=250$ subjects; $\quad \#(G)=750 ; \quad \#(A)=300 ; \quad \#(\mathrm{I})=700 ; \quad \#(\mathrm{~T})=1000$.

Let us preview what an imperfect detector would inform in the specific case in which a perfect detector finds $\#(B \cap A)=100$ subjects.

In all these examples the imperfect detector always has the characteristics $\beta=\gamma=0.1$.

Equation (1) is solved for $\#(\operatorname{Pos})$ to find that $\#(\operatorname{Pos})=\#(B) \cdot(1-\beta-\gamma)+\beta . \#(T)=300$ subjects. Similarly, from Equation (5): $\#(\operatorname{Pos} \cap A)=(1-\beta-\gamma) . \#(B \cap A)+\beta . \#(A)=110$ subjects.

\section{How a careful operator handles the output of imperfect detector}

In the above, we started from the truth (given by a perfect detector) to arrive to the untruth (given by an imperfect detector). Let us see how a careful operator goes backward, from the untruth to the truth.

A careful operator is given the following data from an experiment with an imperfect detector whose characteristics are known to be $\beta=0.1 ; \gamma=0.1$ :

number of subjects doing the activity $=\#(\mathrm{~A})=300$;

number of subjects not doing the activity $=\#(\mathrm{I})=700$;

$\#(\mathrm{Pos} \cap \mathrm{A})=110$ subjects; $\#(\mathrm{Neg} \cap \mathrm{A})=190$ subjects;

$\#(\operatorname{Pos} \cap \mathrm{I})=190$ subjects; $\#(\mathrm{Neg} \cap \mathrm{I})=510$ subjects.

The operator does not care about writing the contingency table corresponding to the above values but directly starts writing the corrected table (Table VII). Let us follow the operator's work:

total number of subjects in sample $=\#(T)=\#(A)+\#(I)=1000$ subjects;

total number of positive subjects $=\#(\operatorname{Pos})=\#(\operatorname{Pos} \cap A)+\#(\operatorname{Pos} \cap \mathrm{I})=300$ subjects;

total number of negative subjects $=\#(\mathrm{Neg})=\#(\mathrm{Neg} \cap \mathrm{A})+\#(\mathrm{Neg} \cap \mathrm{I})=700$ subjects;

confirmation: \#(Pos) $+\#(\mathrm{Neg})=1000$ subjects;

from Equation (1): total number of baddies $=\#(\mathrm{~B})=[\#(\mathrm{Pos})-\beta . \#(\mathrm{~T})] /(1-\beta-\gamma)=$ $=250$ baddies in set $\mathrm{T}$;

total number of goodies $=\#(G)=\#(T)-\#(B)=750$ goodies in set $T$;

fraction of baddies in sample $\mathrm{T}$ (prevalence) $=\alpha=\#(\mathrm{~B}) / \#(\mathrm{~T})=0.25$;

$($ from Equation $(6): \#(B \cap A)=[\#(\operatorname{Pos} \cap A)-\beta . \#(A)] /(1-\beta-\gamma)=100$ 
G.Gambirasio

Correction for detector's specificity and sensitivity in contingency tables

Table VII - Corrected contingency table of a specific experiment

\begin{tabular}{|c|c|c|c|}
\hline $\begin{array}{l}\text { Effect } \rightarrow \\
\text { Cause } \downarrow\end{array}$ & Subjects in B & Subjects in set $\mathbf{G}$ & Totals \\
\hline $\begin{array}{c}\text { Active subjects } \\
\text { A }\end{array}$ & $\begin{aligned} \mathrm{C}_{11}= & \#(\mathrm{~B} \cap \mathrm{A})= \\
& =100\end{aligned}$ & $\begin{aligned} C_{12}= & \#(G \cap A)= \\
& =200\end{aligned}$ & $\begin{array}{c}\text { Total number of } \\
\text { active subjects } \\
\#(\mathrm{~A})=300\end{array}$ \\
\hline $\begin{array}{c}\text { Inactive subjects } \\
\text { I }\end{array}$ & $\begin{array}{c}\mathrm{C}_{21}=\#(\mathrm{~B} \cap \mathrm{I})= \\
=150\end{array}$ & $\begin{array}{c}\mathrm{C}_{22}=\#(\mathrm{G} \cap \mathrm{I})= \\
=550\end{array}$ & $\begin{array}{c}\text { Total number of } \\
\text { inactive subjects } \\
\#(I)=700\end{array}$ \\
\hline Totals & $\begin{array}{l}\text { Total number of } \\
\text { baddies in } \mathrm{T} \\
\#(\mathrm{~B})=250\end{array}$ & $\begin{array}{l}\text { Total number of } \\
\text { goodies in T } \\
\#(\mathrm{G})=750\end{array}$ & $\begin{array}{c}\text { Total number of } \\
\text { subjects } \\
\#(T)=1000\end{array}$ \\
\hline
\end{tabular}

Having written Table VII by following the methodology, the careful operator knows that Table VII is the same table as a perfect detector would have written. Then the operator can go on computing $\operatorname{dep}(\mathrm{B} \mid \mathrm{A})$ and even use the probabilistic flavor if he/she so wishes. All this is shown on paper $\left({ }^{1}\right)$ and it shell no be repeated here.

If the operator does not wish to restrict the work to one specific case, he/she changes cell $\mathrm{C}_{11}$ of Table VII into the independent variable $x$, as shown on Table VIII .

The operator then computes:

Proportion $\mathrm{P}(\mathrm{B} \mid \mathrm{A})=\#(\mathrm{~B} \cap \mathrm{A}) / \#(\mathrm{~A})=\mathrm{x} / 300$;

Proportion $\mathrm{P}(\mathrm{B} \mid \mathrm{I})=\#(\mathrm{~B} \cap \mathrm{I}) / \#(\mathrm{I})=(250-x) / 700$.

Independence occurs when $\mathrm{P}(\mathrm{B} \mid \mathrm{A})=\mathrm{P}(\mathrm{B} \mid \mathrm{I})$, giving the corresponding value $x_{0}=75$.

Table VIII - Modified contingency table to describe a range of experiments (running variable is $x$ )

\begin{tabular}{|c|c|c|c|}
\hline $\begin{array}{c}\text { Effect } \rightarrow \\
\text { Cause } \downarrow\end{array}$ & Subjects in set B & Subjects in set G & Totals \\
\hline $\begin{array}{c}\text { Active subjects } \\
\text { A }\end{array}$ & $\begin{array}{c}\mathrm{C}_{11}=\#(\mathrm{~B} \cap \mathrm{A})=x \\
0 \leq x \leq 250\end{array}$ & $\begin{array}{c}\mathrm{C}_{12}=\#(\mathrm{G} \cap \mathrm{A})=300-x \\
=\end{array}$ & $\begin{array}{c}\text { Total number of } \\
\text { active subjects } \\
\#(\mathrm{~A})=300\end{array}$ \\
\hline $\begin{array}{c}\text { Inactive subjects } \\
\text { I }\end{array}$ & $\begin{array}{c}\mathrm{C}_{21}=\#(\mathrm{~B} \cap \mathrm{I})= \\
=250-x\end{array}$ & $\begin{array}{c}\mathrm{C}_{22}=\#(\mathrm{G} \cap \mathrm{I})= \\
=450+x\end{array}$ & $\begin{array}{c}\text { Total number of } \\
\text { inactive subjects } \\
\#(\mathrm{I})=700\end{array}$ \\
\hline Totals & $\begin{array}{c}\text { Total number of } \\
\text { baddies in T } \\
\#(\mathrm{~B})=250\end{array}$ & $\begin{array}{c}\text { Total number of } \\
\text { goodies in T } \\
(\mathrm{G})=750\end{array}$ & $\begin{array}{c}\text { Total number of } \\
\text { subjects } \\
\#(\mathbf{T})=\mathbf{1 0 0 0}\end{array}$ \\
\hline
\end{tabular}


G.Gambirasio

Correction for detector's specificity and sensitivity in contingency tables

As expected, Table VIII is the same as Table 2 of paper $\left({ }^{1}\right)$, a table produced by a perfect detector. From Table VIII a careful operator may compute dependence evaluator as a function of $x$ :

$\operatorname{dep}(\mathrm{B} \mid \mathrm{A})=[\mathrm{P}(\mathrm{B} \mid \mathrm{A})-\mathrm{P}(\mathrm{B} \mid \mathrm{I})] /[\mathrm{P}(\mathrm{B} \mid \mathrm{A})+\mathrm{P}(\mathrm{B} \mid \mathrm{I})]=[10 . x-750] /[4 . x+750]$.

The independence value is $x_{0}=\#(\mathrm{~B})$.\#(A) / \#(T) $=75$ and it does not depend on detector's characteristics.

\section{The case of the careless operator}

The careless operator takes all positive subjects as they were all baddies.

The running variable appearing on cell $\mathrm{C}_{11}$ of the corresponding contingency table (Table IX) is named $y=\mathrm{C}_{11}=\#(\operatorname{Pos} \cap \mathrm{A})$.

Table IX - Contingency table written by a careless operator

\begin{tabular}{|c|c|c|c|}
\hline $\begin{array}{c}\text { Effect } \rightarrow \\
\text { Cause } \downarrow\end{array}$ & $\begin{array}{c}\text { Subjects in } \\
\text { Pos }\end{array}$ & $\begin{array}{c}\text { Subjects in } \\
\text { Neg }\end{array}$ & Totals \\
\hline $\begin{array}{c}\text { Active subjects } \\
\text { A }\end{array}$ & $\begin{array}{c}\mathrm{C}_{11}= \\
=\#(\operatorname{Pos} \cap \mathrm{A})=y\end{array}$ & $\begin{array}{c}\mathrm{C}_{12}= \\
=\#(\mathrm{Neg} \cap \mathrm{A})= \\
=300-y\end{array}$ & $\begin{array}{c}\text { Total number of } \\
\text { active subjects } \\
\#(\mathrm{~A})=300\end{array}$ \\
\hline $\begin{array}{c}\text { Inactive subjects } \\
\text { I }\end{array}$ & $\begin{array}{c}\mathrm{C}_{21}= \\
=\#(\mathrm{Pos} \cap \mathrm{I})= \\
=300-y\end{array}$ & $\begin{array}{c}\mathrm{C}_{22}= \\
=\#(\mathrm{Neg} \cap \mathrm{I})= \\
=400+y\end{array}$ & $\begin{array}{c}\text { Total number of } \\
\text { inactive subjects } \\
\#(\mathrm{I})=700\end{array}$ \\
\hline Totals & $\#(\mathrm{Pos})=300$ & $\#(\mathrm{Neg})=700$ & $\begin{array}{c}\text { Total number of } \\
\text { subjects } \\
\#(\mathbf{T})=\mathbf{1 0 0 0}\end{array}$ \\
\hline
\end{tabular}

Let us check independence, which will occur at $y=y_{0}$ :

$\mathrm{P}(\operatorname{Pos} \mid \mathrm{A})=\#(\operatorname{Pos} \cap \mathrm{A}) / \#(\mathrm{~A})=y / \#(\mathrm{~A})$;

$\mathrm{P}(\operatorname{Pos} \mid \mathrm{I})=\#(\operatorname{Pos} \cap \mathrm{I}) / \#(\mathrm{~A})=[\#(\operatorname{Pos})-y] / \#(\mathrm{I})$.

Condition for independence is

$y_{0} / \#(\mathrm{~A})=\left[\#(\mathrm{Pos})-y_{0}\right] / \#(\mathrm{I})$, which gives $y_{0}=\#(\mathrm{Pos}) \#(\mathrm{~A}) / \#(\mathrm{~T})$.

Since \#(Pos) depends on the detector's characteristics, so does $y_{0}$.

In the current example, the value of $y$ corresponding to independence is $y_{0}=90$. Dependence evaluator is computed by the careless operator by the formula

$\operatorname{dep}(\operatorname{Pos} \mid \mathrm{A})=[\mathrm{P}(\operatorname{Pos} \mid \mathrm{A})-\mathrm{P}(\operatorname{Pos} \mid \mathrm{I})] /[\mathrm{P}(\operatorname{Pos} \mid \mathrm{A})+\mathrm{P}(\operatorname{Pos} \mid \mathrm{I})]$. The result is:

$$
\operatorname{dep}(\operatorname{Pos} \mid \mathrm{A})=[10 \cdot y-900] /[4 \cdot y+900] \text {. }
$$

Value of $y_{0}$ is a linear function of $\beta$ and $\gamma$. The greater are these characteristics, the more distant $\operatorname{dep}(\operatorname{Pos} \mid \mathrm{A})$ becomes from $\operatorname{dep}(\mathrm{B} \mid \mathrm{A})$ and, obviously, the less useful such detector turns out to be as a tool in analyzing effects like drug taking upon diseases. 
G.Gambirasio

Correction for detector's specificity and sensitivity in contingency tables

Dependence evaluators $\operatorname{dep}(\mathrm{B} \mid \mathrm{A})$ (the correct one) and $\operatorname{dep}(\operatorname{Pos} \mid \mathrm{A})$ (the wrong one) are both shown on Figure 10. If a different detector were used, with different characteristics, $y_{0}$ and $\operatorname{dep}(\operatorname{Pos} \mid \mathrm{A})$ would change accordingly.

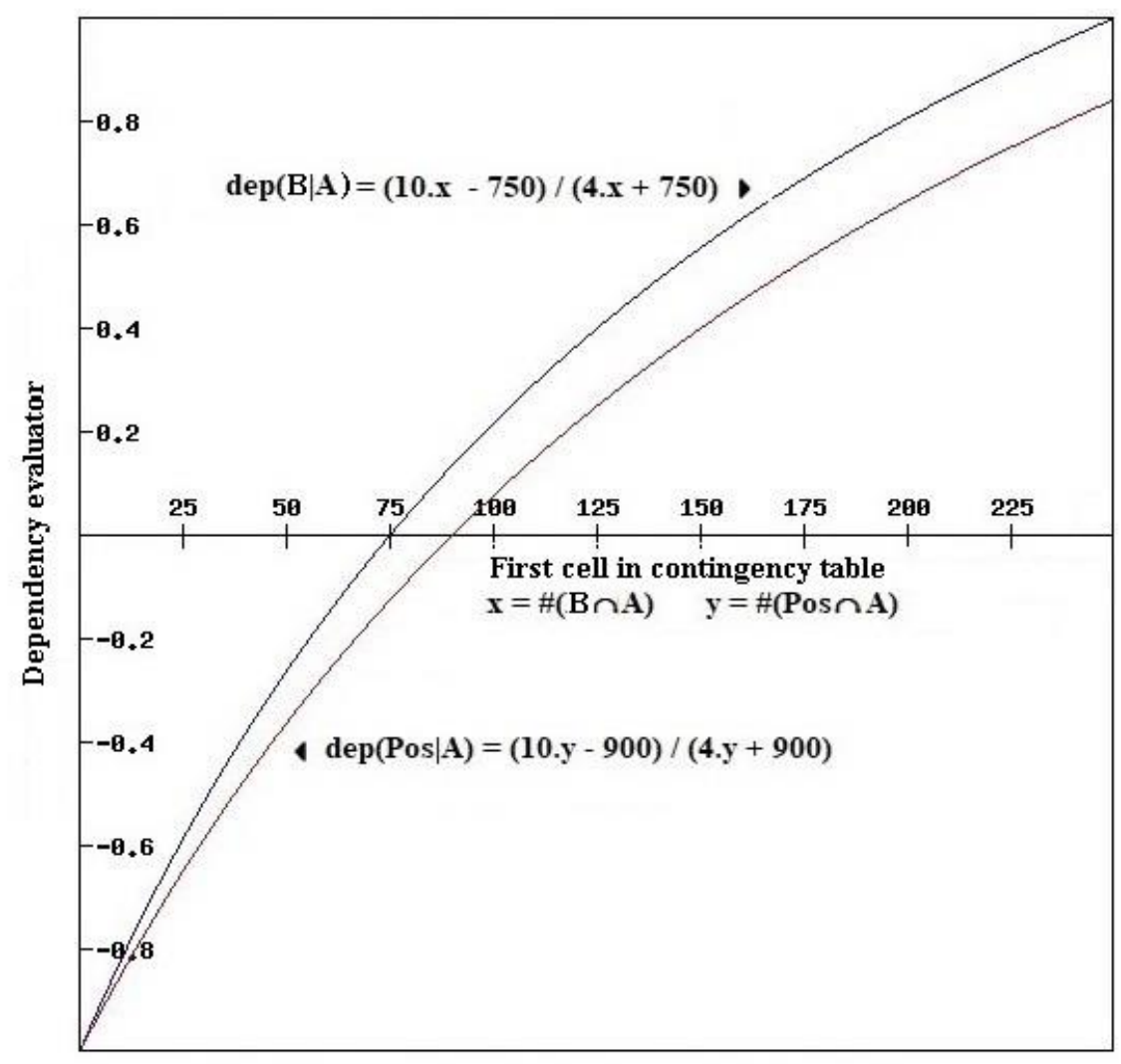

Fig. 10 - Dependency evaluators $\operatorname{dep}(\mathrm{B} \mid \mathrm{A})$ and $\operatorname{dep}(\operatorname{Pos} \mid \mathrm{A})$ as function of first cell $\left(\mathrm{C}_{11}\right)$ value in the corresponding contingency tables.

\section{CONCLUSION}

The methodology developed in this paper with aim to correct the errors due to detector's specificity and sensitivity is completely effective when applied to contingency tables analysis. It is only partially effective when applied to identify diseased subjects .

\section{REFERENCES}

1 - Gambirasio, G. A deterministic approach to contingency tables

DOI: $10.31219 /$ osf.io/s94zr 